\title{
La prensa infantil y juvenil como fenómeno educativo en España
}

\author{
Laura LÓPEZ ROMERO \\ Universidad de Málaga \\ lauralopezr@uma.es \\ Isabel BORDA CRESPO \\ Universidad de Málaga \\ borda@uma.es
}

Recibido: 9 de diciembre de 2014

Aceptado: 9 de enero de 2015

\begin{abstract}
Resumen comportamiento social y en su finalidad de despertar la curiosidad y la imaginación.

Palabras clave: Prensa infantil y juvenil en España. Educación lectora. Escuela y Familia.

\section{Press for children and pre-adolescents as an educational phenomenon in Spain}

Este artículo analiza la oferta actual de prensa infantil y juvenil en España para conocer cuál es la realidad de este sector y cuáles son sus finalidades a través de un análisis cuantitativo y cualitativo. El foco de estudio se centra en las cabeceras con propósito educativo, descartando las de índole comercial. Para ello se ha revisado sus casi dos siglos de existencia para encontrar sus constantes en una oferta que se ha caracterizado por su dinamicidad. Como herramienta informal de educación, pretende conquistar a un sector de la población muy heterogéneo, entre 2 a 18 años. El poder socializador de la prensa infantil se refuerza en su capacidad para fomentar la lectura; en el aprendizaje evolutivo con respecto al

\begin{abstract}
This article analyses the current demand for child and pre-adolescent press in Spain in order to identify the sector's features and its objectives, using a quantitative and qualitative analyses. It focuses on the press containing an educational aim, and which avoids commercial headlines. Two centuries of publications have been revised, in recognition of the large quantity of material that has been made available to the public over that time. As an informal educational tool, the target audience is heterogeneous, between the ages of 2 and 18. The socializing power of the press is reinforced by promoting reading, progressive learning related to social behaviour and its ability to awaken curiosity and the imagination.

Keywords: Child and pre-adolescent press in Spain, Educational reading, School, Family.

\section{Referencia normalizada}

LÓPEZ ROMERO, Laura y BORDA CRESPO, Isabel (2015): "La prensa infantil y juvenil como fenómeno educativo en España”. Estudios sobre el Mensaje Periodístico. Vol. 21, Núm. 2 (julio-diciembre), págs.: 1081-1097. Madrid, Servicio de Publicaciones de la Universidad Complutense.
\end{abstract}

\section{Sumario}

1. Introducción. Estado de la cuestión. 2. Objetivos y metodología. 3. La lectura de la prensa infantil y juvenil en el siglo XXI. 4. Identificación del fenómeno educativo en la prensa infantil y juvenil. 5. Naturaleza, contenidos y propósitos educativos. 6. Fortalezas y debilidades del sector. 7. Conclusiones. 8. Referencias bibliográficas.

\section{Introducción. Estado de la cuestión}

Al estudiar las publicaciones periódicas para la infancia y la juventud a lo largo de los casi dos siglos de existencia en España, comprobamos la dificultad que acompaña la reflexión de la literatura infantil, como producto estético dirigido a la infancia. Para 
poner límites a este concepto necesitamos incorporar al entramado de ideas propias la misma idea de infancia, juventud, cultura, educación, psicología, sexo, arte, historia y literatura, entre otros. Estudiar la relación que se establece entre el receptor infantil y juvenil con el producto estético a él dirigido nos obliga a mantener un difícil equilibrio entre lo educativo, la información y el entretenimiento (Borda, 2006: 35). En el caso de la prensa infantil, los agentes socializadores de la familia y la escuela se comportan de la siguiente manera: la familia delega su papel crítico y evaluador de este producto que consumen las jóvenes generaciones en base a la suposición, acertada qué duda cabe, de que fomenta el hábito lector. Y la escuela ofrece resistencia porque este producto a lo largo de los casi dos siglos de su existencia en nuestro país ha ido manifestando cada vez más abiertamente su poder como agente educativo informal, y por tanto alejado de la práctica formal y académica de lectura. Y así es como el lector infantil se encuentra solo ante la oferta de prensa y revistas y, sobre todo, ante el contenido ideológico que subyace a las noticias, artículos y otros apartados de la prensa infantil.

Es innegable que si queremos una prensa infantil de calidad necesitamos contar con estudios actualizados que nos permitan conocer en profundidad qué valores ideológicos subyacen en las revistas y en la prensa infantil y juvenil, qué modelos de infancia y/o juventud les proponen a su audiencia, así como qué patrones socializadores encuentran en su lectura. Y ello desde una perspectiva tanto diacrónica como sincrónica.

Al intentar acotar el término de prensa infantil lo primero que llama la atención es su aparente difusión. Y decimos aparente porque si bien la definición de prensa infantil resulta clara: "El conjunto de revistas y periódicos que aparecen de manera periódica (semanal, quincenal, mensual...) y que va dirigido potencialmente a un público infantil y juvenil (entre 2 y 18 años)", sigue estando sujeta a debate. Para Cosín Puyol (2003: 30), sorprende que englobe tanto publicaciones periódicas de humor, aventuras, y/o dibujos animados, historietas y/o tebeos o cómic como revistas propiamente dichas, dirigidas tanto a un público infantil como juvenil, así como también suplementos dirigidos a la infancia en revistas o prensa de adultos.

Un espacio de encuentro lo constituye su consideración de agente difuso de socialización o instrumento informal al servicio de una ideología determinada. Así lo expresan las autoras del estudio acerca de las influencias de las revistas juveniles en la sexualidad de los y las adolescentes (Rubio et al. 2008: 12): "Las revistas juveniles se han manifestado como un agente con una gran capacidad de influencia en la transmisión de información relativa a la sexualidad para los y las jóvenes. Esto se debe tanto a su naturaleza de objeto de culto desde edades tempranas, como por ser un medio informal y difuso que ha ido incrementado su impacto y, con ello, su potencial como elemento formativo".

Si seguimos la pista a los orígenes de estas publicaciones periódicas podremos entender mejor qué finalidad o finalidades cumplieron en su origen, para posteriormente ver cómo y por qué ha ido evolucionando en nuestro país este tipo de publicaciones a lo largo de los casi dos siglos de sus existencia, hasta posicionarse como claro instrumento de educación informal. 
La prensa infantil surge en España en el siglo XVIII con el periódico La Gaceta de los niños (1798). Con una impresión cuidada, sin ilustraciones, con una distribución por suscripción y un fin pedagógico, nace con el sobrenombre de Principios generales de moral, ciencias y artes, acomodados a la inteligencia de la primera edad. Inspirado en el periódico francés Correo de los niños de Jouffret, se dirige como éste a un público acomodado, preferentemente burgués por los valores que transmitía. La intención de este periódico escolar era crear una literatura para niños (Bravo Villasante, 1979: 52).

Otros periódicos infantiles del siglo XIX fueron El mentor de la infancia (18431845 ) donde los cuentos se alternan con la historia sagrada y anécdotas de piedad filial, apareciendo por primera vez, los juegos. Esta publicación salía los domingos y está considerado como la segunda publicación creada para los niños. En 1849 aparece el malagueño El amigo de los niños con contenidos predominantemente pedagógicos, religiosos y morales. Y en 1850 hasta 1851, aparece la publicación El faro de la niñez, enciclopedia general de instrucción primaria, moralidad y recreo infantil. Se trata de un tipo de prensa de educación, publicación oficial de Socorros Mutuos de Instrucción Pública.

Y ya en la segunda mitad del siglo XIX, encontramos La niñez: Revista de Educación y recreo (1879-1882), revista que ofrece a sus lectores una enseñanza más amena de la moral religiosa y las buenas costumbres, ilustrándose con grabados xilográficos; Los niños: revista de educación y recreo (1870-1872), que utiliza las primeras viñetas con gran expresividad gráfica vinculadas para contar historias; La primera edad (1873), que se idea para llegar a los niños más pequeños de la casa, con una lectura escogida, moral e instructiva, además de ilustraciones y figurines para niñas y sus muñecas. En 1875 nace La educación Pintoresca, editado según el modelo de los periódicos femeninos de la época. Incorpora láminas litografiadas y está dirigido a los adultos para obtener su aprobación. Colaboran autores de prestigio como Fernán Caballero y Antonio Trueba.

La manifiesta intención pedagógica de la casi totalidad de las publicaciones que durante el siglo XIX se dirigían a la infancia nos habla de publicaciones infantiles subsidiarias de lo pedagógico y didáctico en el sentido de moralizante e instructivo dado que están asociadas a la escolarización de los niños y niñas (Borda Crespo, 2002: 19). No olvidemos que este producto estético pretende dirigirse en el siglo XIX y albores del siglo XX, a un receptor cuyas necesidades de ocio y recreativas aun no están muy reconocidas en nuestro país, casi comenzamos a identificar en este momento histórico sus necesidades educativas. Para Carmen Bravo Villasante (1979: 55), la pedantería de la literatura del periódico infantil "era semejante a la del perceptor y ayo, a la del dómine y el maestro. La literatura infantil sigue siendo una rama monstruosa de la pedagogía".

Ya en el siglo XX encontramos una publicación periódica infantil que ha marcado a generaciones de españoles y en cuyas páginas confluían las vanguardias, las firmas más importantes de la literatura y los trazos de los mejores ilustradores del momento. Nos referimos a Gente Menuda, suplemento de la revista Blanco y negro, que ve su primer número en 1904. Apreciamos en esta primera etapa de la publicación el paso 
de la concepción moralizante de este tipo de publicaciones en el siglo XIX hacía una concepción más lúdica y recreativa, y en la que la imagen gana terreno e importancia. En su décimo aniversario abandona los kioscos para aparecer de nuevo en 1928, también como suplemento de Blanco y Negro, hasta 1932, año en que se convirtió en suplemento independiente y gratuito, ganándose la consideración de mejor suplemento infantil. Como dato revelador, recordar que el alma literaria de este suplemento fue Elena Fortún con su emblemático personaje Celia. Y junto a ella, el alma gráfica, Francisco López Rubio. En torno a ellos se congregaron escritores de la talla de Antoniorrobles, Magda Donato, Manuel Abril y dibujantes como Salvador Bartolozzi, Climent, Tauler y otros.

La primera etapa de Gente menuda termina justo al comenzar la guerra civil española. Reaparece, inaugurando una segunda época, en 1976 hasta 1978, como suplemento de $A B C$, e incluyó series de Flash Gordon Pinin, y Dick, el artillero, así como adaptaciones gráficas de series televisivas tan populares como Heidi y Vickie el vikingo. El 1989 y hasta 1999, vio su tercera época, incluyendo el suplemento historietas de Blueberry, Conan el Bárbaro y el conocidísimo Mortadelo y Filemón.

Con este esbozo de lo que ha sido la prensa periódica infantil en España durante desde sus orígenes hasta el siglo XX interesa poner de relieve dos cuestiones. En primer lugar, la extraordinaria vitalidad de este tipo de publicaciones dirigidas a la infancia. Se da la paradoja de que a pesar de tratarse de una publicación que se distribuye por suscripción y que está dirigida a un público infantil de clase media, se trata de un medio de comunicación con antecedentes fuertemente populares, solo tenemos que pensar en la impresión de la aleluyas en los siglo XVIII y XIX (Martín, 2011). De ahí su consideración como instrumento informal de educación.

En segundo lugar, destacamos el hecho de que hablamos de un medio de comunicación que pretende ofrecer a un público lector infantil y/o juvenil un material de lectura que instruyéndole le distraiga. No podemos olvidar que en la primera mitad del siglo XIX aumenta significativamente el público lector entre otras razones por la escolarización en masa de este sector de la población, lo cual demanda material de lectura apropiados para ellos (Quintana Cabanas, 1981: 63) ${ }^{1}$. Además y tal y como recoge Fuentes (2003: 724), las innovaciones tecnológicas introducidas en el trabajo de impresión contribuirán al abarramiento de la edición, con lo que se puede incorporar la imagen al texto. La presencia in crescendo de la imagen/ilustración en sus páginas posibilitará el predominio de lo recreativo y, por tanto, de lo informal.

La incorporación de la prensa infantil a la oferta de lectura para una infancia que recién se incorporaba a una escolarización masiva pone sobre el tapete el afán de los

1 Como medio formal de comunicación posee los siguientes elementos educativos: es elemento dinamizador de la lectura; abre el horizonte personal de los niños y niñas; facilita el aprendizaje evolutivo del comportamiento social; enriquece el vocabulario personal; aporta mayor conocimiento de cosas y hechos; proporciona material para enlaces causales, psicológicos y lógicos; mueve a la libre aceptación de un esfuerzo de atención y reiteración lectora; proporciona una visión simplificada e interpretada de la realidad; permite aprender convivencia y sociabilidad y por último, la imagen tiene un poderoso poder de sugerir. 
medios por atraer a este público con un material de lectura que trascendiese lo estrictamente escolar. De ahí que llame la atención la variedad de contenidos de estos periódicos: desde biografías, ciencias, educación, geografía, historia, arte, literatura, religión. Partimos del hecho de que la literatura que se dirigía en un primer momento a la infancia era una literatura eminentemente de tipo moral, religiosa, en una palabra, instructiva. De ahí el intento de ofrecerle al menos aparentemente un contenido variado con la intención de fidelizar a un público con poca o nula fuerza social. Por esta razón estos periódicos no lograban encontrar una continuidad en un público que no se sentiría muy atraído por un contenido con tan clara intención educativa y moralizante. Mucha lección variada y poco entretenimiento, en definitiva.

Al subir las cotas de alfabetización hacia el año 1910, el potencial del público lector infantil se perfila como susceptible grupo consumidor, a lo que unimos el gusto de los niños por acercarse a las historietas. Los pedagogos y los moralistas se retraen permitiendo así que los niños puedan acercarse a estas revistas. La evolución de las técnicas de fotograbado concluyó en una rápida traslación de las historietas de la prensa satírica dirigida a adultos hacia la prensa dirigida a la infancia. En revistas como En Patufet, Gente Menuda o Infancia, florece un modo de hacer historietas más suelto, más libre y más expresivo, atendiendo a la necesidad de ofrecer a los niños un nuevo tipo de publicaciones sin servidumbres pedagógicas (Martín, 2004: 56).

Revilla (1981: 35) estudia el lugar destacado del TBO en la historia de la prensa infantil española. Su tipología popular, un precio asequible, una amplísima difusión con una capilaridad en la distribución que garantiza su gran tiraje, consiguen hacer de esta publicación un instrumento para divertir. Para Revilla, el que no pareciese en cada número ni fecha ni número, hacía posible sortear el escollo de los permisos de edición. El TBO llega a 1979 como "Caso excepcional de esclerosis sociológico". Esta presencia de la historietas en formato cómic ha llegado hasta las revistas actuales, siendo más frecuente en revistas destinadas a un público infantil y en su mayoría protagonizadas por personajes de series de dibujos animados (AVACU, 2010: 17).

\section{Objetivos y metodología}

El principal propósito de esta investigación es estudiar la prensa para niños y jóvenes, conocida como prensa infantil y juvenil, como fenómeno educativo en España. El foco de estudio no se ha centrado en analizar las publicaciones de índole comercial, sino aquellas que por su naturaleza y contenido se nutren de propósitos educativos como la promoción de la lectura y la adquisición de conocimientos a través de la curiosidad y la imaginación, etc. Para discernir el corpus que conforman las publicaciones integradas en este estudio es importante resaltar que no se engloban dentro de los términos prensa pedagógica o prensa educativa. En el primero de los casos se trataría de un tipo de periodismo elaborado dentro de las aulas, mientras que el concepto de prensa educativa corresponde a una especialización del periodismo que trata temas relacionados con la educación y por lo tanto orientado a un lector relacionado con la academia. En este sentido, la prensa infantil y juvenil constituye el conjunto de publicaciones -en su mayoría revistas-, dirigidas a un lector joven, dentro de las cuales, existe un sector que desarrolla una actividad con fines didácticos alejados de la pro- 
moción publicitaria que caracteriza al resto de productos periodísticos destinados a estas edades.

El método de trabajo empleado ha sido el análisis de contenido para el cual se ha trabajado con fichas de vaciado para analizar el contenido textual y las ilustraciones así como el diseño. El trabajo se ha completado con herramientas cualitativas que han permitido conocer la identidad empresarial de este mercado editorial, mediante la entrevista en profundidad a tres profesionales del sector, en particular, a redactores jefes de las editoriales Bayard, Panini y $\mathrm{J}+\mathrm{G}$.

Así mismo, y como punto de referencia se ha tomado como estructura comparativa el sector de la prensa infantil y juvenil en Francia, país que constituye uno de los ejemplos más avanzados en Europa.

\section{La lectura de prensa infantil y juvenil en el siglo XXI}

La prensa infantil a principios del siglo XXI se aproxima a un modelo periodístico caracterizado por el uso de diferentes géneros, desde noticias, entrevistas, reportajes, y la inclusión de una amplia gama de contenidos, tanto informativos como recreativos o lúdicos, con un predominio claro de la imagen sobre el texto y dirigidos a niños y jóvenes y que como dice Cosín Puyol (2003: 31), no puede considerarse sólo un medio de entretenimiento para el niño o el joven porque ofrece una información, unas ideas, unos valores, que incidirán en sus actitudes personales y sociales. Su extraordinario poder socializador le permitiría a objetivos escolares pero para ello debería romper las resistencias de la escuela para incorporar aquello que provenga de fuera de la propia estructura escolar (Abril, López, 2000: 25).

Según la investigación realizada por AVACU y la Dirección General de Evaluación, Innovación y Calidad Educativa en el año 2010, se ha producido un aumento de los productos destinados a los niños y jóvenes, convirtiéndose así en un objetivo claro y eficaz del sector productivo y de la distribución. La razón es clara, el aumento de su poder de decisión en la familia. Tras estudiar 60 revistas dirigidas a la infancia y la juventud, ver qué papel juegan, qué valores transmiten, qué modelos de identificación proponen, qué temas recogen, qué tratamientos les dan, entre otros aspectos, y encuestar a jóvenes de entre 9 y 17 años, se llega a los siguientes resultados: más de la mitad, el 57\%, afirma leer revistas infantiles y/o juveniles, siendo las chicas con un $79 \%$ las grandes lectoras de estas revistas.

Los jóvenes se acercan a estas revistas con un propósito claramente lúdico o de entretenimiento. Según el trabajo de Rubio Gil et al. (2008: 15) los adolescentes de entre 10 a 14 años, leen estas revistas en primer lugar para entretenerse, constituyendo un vehículo de comunicación con sus iguales. Su poder socializador, aunque difuso dado que entre sus funciones no se encuentra prioritariamente la educativa, se concreta en su función como preparadores para la vida adulta en aspectos tales como la sexualidad o la moral, siendo los contenidos los propios de una subcultura juvenil.

En relación a los contenidos, el informe realizado por AVACU concluye que la lectura de este tipo de publicaciones, sin un análisis crítico y selectivo, por parte de adultos competentes, y sin la compensación de lectura de libros, fomenta un consumismo sin criterio y, lo más alarmante, son contenidos que perpetúan la discriminación de gé- 
nero. Recordemos como veíamos al prinicipio de estas líneas, que los padres y madres ven con buenos ojos el consumo de estas revistas por parte de los jóvenes adolescentes porque piensan que les fomenta el hábito lector (Rubio Gil et al., 2008: 31).

Según los datos de la Encuesta General de Medios de 2004-2005 y comparándolos con los de 2013-2014, las revistas siguen siendo un producto cultural y el medio de comunicación característico de la adolescencia. En estos diez años ha pasado de ser uno de los medios hegemónicos en estas etapas de la vida, después de la televisión y seguido muy cerca de Internet, a ocupar un tercer puesto (con un 45,4), detrás de Internet con un 86,1 y la televisión con un 84,4 .

\section{Identificación del fenómeno educativo en la prensa infantil y juvenil}

El grueso de la comercialización de prensa infantil y juvenil se concentra principalmente en revistas asociadas a películas, series televisivas, dibujos animados y videojuegos. En cualquier punto de venta son fácilmente accesibles. El objeto de atracción de estas publicaciones está asociado a un entretenimiento directamente relacionado con el consumismo generado por la publicidad que se incorpora en sus páginas. En este tipo de productos, el lector desempeña un "disfrute pasivo" (Espiño, 2014) debido a la inexistencia de contenidos que aboguen por aportar un aprendizaje basado en la promoción de la lectura o en la adquisición de conocimientos a través de juegos, historias, cuentos, experimentos científicos, etc.

Para el público medio lector, la existencia de una prensa con fines educativo, destinado a un público infantil y juvenil es bastante desconocida. Apenas algunas de las revistas que van a ser analizadas pueden adquirirse en algunos puntos de ventas, principalmente en librerías o puestos de prensa ubicados en centros comerciales. Los quioscos apenas incorporan este tipo de producto y por lo tanto su comercialización sigue estando más orientada a la suscripción que a la venta directa de ejemplares sueltos. Ni siquiera la OJD audita las revistas objeto de estudio de este artículo. Tan sólo da cuenta de prensa infantil y juvenil con un total de seis cabeceras que se engloban entre las de índole comercial: Clan Revista, Dibus!, Pelopicopata, Peppa, Revista Oficial Nintendo, El Tátano, Cavall Fort (estas dos últimas escritas en catalán).

La oferta de prensa orientada a un público infantil y juvenil con un objetivo educativo en España es reducida en cuanto al número de cabeceras que se ofrecen. Este panorama beneficia al sector editorial ya que la competencia es más baja, sin embargo, según apunta Eva Frutos, redactora jefe de las revistas Okapi y Reportero Doc, de la editorial Bayard, "en estos momentos apenas tenemos competencia y, al parecer, eso nos ha perjudicado más que ayudarnos. El haber tenido competencia, por jemplo, de Muy interesante junior, nos ayudó a que se vendieran más Reportero Doc y Okapi"'. Qué duda cabe que este tipo de revistas requiere de un empuje publicitario promocional, y por ende, un aumento de lectores. En el caso de Bayard en Francia, ya hace años que compró a su competidor más directo, Milan, que ahora es una de las marcas, a un precio más asequible, del grupo Bayard Presse.

2 Entrevista a Eva Frutos, redactora jefe de las revistas Okapi y Reportero Doc. 26 de noviembre de 2014. 
La falta de competencia es un tema recurrente en las entrevistas a los redactores jefes. José Pardina, el que fuera director de la revista Muy Interesante Junior, desaparecida en 2011, argumentaba al respecto que "no hay en el quiosco revista alguna como ésta. Lamentablemente no tenemos competencia"”.

La AIMC elaboró en el año 2008 un informe sobre audiencia infantil y juvenil de medios en España. En el apartado de lectura de prensa se identificaron dos revistas de carácter educativo: Muy Interesante Junior y Leo Leo. La primera de ellas, editada por la editorial $\mathrm{J}+\mathrm{G}$ cerró en el año 2011 mientras que la segunda es editada por Bayard y continua actualmente su venta. El grueso de revistas que se consumen semanal o mensualmente se corresponde con productos más comerciales como Plastation 2, Barbie, Art Attack o Nintendo Accion. Si bien estos resultados confirman nuevamente la escasa penetración del sector entre la población infantil y juvenil, al menos es alentador comprobar que en el listado de las revistas más leídas en los últimos 6 meses consta el producto educativo Leo Leo. (AIMC, 2008: 29).

A continuación se desglosa en la Tabla 1 las cabeceras objeto de estudio en esta investigación, así como su temática, la edad a la que van dirigidas, su periodicidad y la editorial.

Tabla 1. Prensa orientada a un público infantil y adolescente publicada en España. Elaboración propia.

\begin{tabular}{|c|c|c|c|c|}
\hline Revista & Temática & Edad & Periodicidad & Editorial \\
\hline Popi & $\begin{array}{l}\text { Descubrir el vocabulario } \\
\text { Inicio en manualidades }\end{array}$ & Desde 1 año & Mensual & Bayard \\
\hline Caracola & $\begin{array}{l}\text { la Inicio de lectura } \\
\text { Recortables }\end{array}$ & Desde 4 años & Mensual & Bayard \\
\hline Leo Leo & Lectura, juegos, naturaleza & Desde 7 años & Mensual & Bayard \\
\hline Reportero Doc & Lectura, juegos, naturaleza & Desde 9 años & Mensual & Bayard \\
\hline Okapi & $\begin{array}{l}\text { Actualidad, entorno social, } \\
\text { lectura, juegos, humor }\end{array}$ & Desde 11 años & Mensual & Bayard \\
\hline $\begin{array}{l}\text { Me gusta el } \\
\text { inglés con } \\
\text { Caracola }\end{array}$ & Nivel inicial & 4-6 años & Mensual & Bayard \\
\hline $\begin{array}{l}\text { I love English } \\
\text { mini }\end{array}$ & Nivel elemental & 7-9 años & Mensual & Bayard \\
\hline $\begin{array}{l}\text { I love English } \\
\text { junior }\end{array}$ & Nivel básico inglés & 9-11 años & Mensual & Bayard \\
\hline I love English & Nivel intermedio inglés & 11-13 años & Mensual & Bayard \\
\hline Today in English & Nivel avanzado inglés & Más de 13 años & Mensual & Bayard \\
\hline $\begin{array}{l}\text { National } \\
\text { Geographic Kids }\end{array}$ & Naturaleza & 7-14 años & Bimestral & Panini \\
\hline imales & $\begin{array}{l}\text { La gran revista del mundo } \\
\text { animal }\end{array}$ & años & Bimestral & Panini \\
\hline El Gancho & Actualidad & 7-13 años & Mensual & Norba \\
\hline
\end{tabular}

${ }^{3}$ Entrevista a José Pardina, director de la revista Muy Interesante Junior. 10 de octubre de 2011. 
Como se aprecia en la tabla 1, la editorial Bayard se configura como la más importante del mercado español al editar el mayor número de cabeceras, denominadas por ellos mismo como "revistas innovadoras y constructivas". Además, cuenta con el respaldo del último Plan para el Fomento de la Lectura en el cual se alienta al consumo de este tipo de revistas para incentivar la lectura entre los más pequeños. Aunque los datos de tirada no están auditados por OJD, la web de la editorial confirma que revistas como Popi cuentan ya con 100.000 seguidores mientras que otra como Caracola alcanza los 150.000 ejemplares (Editorial Bayard, 2014:http://www.bayardrevistas.com). La empresa incluye también la edición de tres revistas en catalán, Cucafera (homóloga de Caracola), Tiroliro (equivalente de Leo Leo) y Reportero Doc. La editorial Panini oferta revistas más orientadas a un consumo comercial. Es el caso de cabeceras como Spider-man, Hot Wheels, Barbie, Monster High, Mundo Pocoyo, etc. Sin embargo, merece especial atención destacar la publicación de National Geographic Kids y la revista Animales.

La autopromoción de este tipo de prensa funciona preferentemente mediante el boca a boca. En ocasiones se utilizan eventos familiares para darse a conocer. No se publicitan a través de la televisión, sin embargo sí en prensa, a través de dominicales. Es el caso de la editorial Bayard, la venta directa es muy reducida, funcionando primordialmente por suscripción. El caso contrario lo encuentramos en National Geographic Kids, cuyos ejemplares sí se venden en quioscos. En el caso de El Gancho, su distribución en gratuita y dirigida a centros docentes ${ }^{4}$.

En Francia, la oferta de cabeceras educativas es pujante y por ende el nivel de competitividad entre ellas. Según un estudio publicado por la Direction du Développement des Médias de 2008, en 2006 existía en Francia un total de 212 cabeceras destinadas al público infantil, entre las cuales se enmarca las comerciales y las educativas. Tanta pluralidad de títulos implica una fuerte demanda y una gran apuesta por la empresa editora por visibilizar su producto frente a los demás. (Consigny, 2009).

A diferencia de España, la mayoría de la prensa francesa de este sector sí está auditada por la OJD y arroja datos de gran relevancia que vienen a confirmar su madurez y su asentamiento en el mercado editorial. Sirvan algunos ejemplos que ilustran esta sólida posición: Astrapi (86.074), J'aime lire (178.999), Okapi (84.630), Popi (102.726), Youpi (92.995). Este conjunto de revistas está clasificado como prensa de pago para el gran público, en la temática de prensa para familia, el cual a su vez se divide en los siguientes subapartados: niños, adolescentes, familia generalista, padres y pedagógicas-educativas. Curiosamente este último apartado corresponde a las cabeceras que tienen por objetivo la enseñanza de una lengua extranjera y la revista Phosphore, editada por Bayard, especializada en el ámbito académico preuniversitario para adolescentes entre 14 a 18 años.

A través de la Tabla 2 se aprecia con claridad la gama tan variada no sólo en edad, sino en también en temáticas.

${ }^{4}$ La revista El Gancho nace en el año 2006. Está editada por la Junta de Andalucía y su ámbito geográfico de difusión se centra en centros docentes. Está destinado a estudiantes entre $1^{\circ}$ y $6^{\circ}$ de Primaria y cuenta con una tirada mensual de 95.000 ejemplares. 
Tabla 2. Prensa orientada a un público infantil y adolescente con fines educativos en Francia. Elaboración propia

\begin{tabular}{|c|c|c|c|}
\hline Revista & Lema / Temática & Edad & Editorial \\
\hline Abricot & Juegos, inicio de la lectura & $2-5$ & Fleurus Presse \\
\hline ARKEO junior & «À la découverte de l'archeologie» & $7-14$ & Faton \\
\hline Bébé Papoum & Juegos, colores, manualidades & $0-3$ & Fleurus Presse \\
\hline Astrapi & $\begin{array}{l}\text { Actualidad, juegos, humor, } \\
\text { bricolaje, cocina, lectura, }\end{array}$ & $7-11$ & Bayard \\
\hline Citoyen junior & $\begin{array}{l}\text { La morale pour tous } \\
\text { Sociedad, actualidad }\end{array}$ & $\begin{array}{l}\text { No } \\
\text { especifica }\end{array}$ & Faton \\
\hline Cosinus & $\begin{array}{l}\text { ciencia (juegos, experiencias, } \\
\text { actualidad) }\end{array}$ & $\begin{array}{l}\text { No } \\
\text { especifica }\end{array}$ & Faton \\
\hline GEO Ado & «Le magazine de notre planéte» & $10-15$ & Milan \\
\hline Histoire junior & $\begin{array}{l}\text { «Le magazine d'histoire pour les } \\
10-15 \text { ans» }\end{array}$ & $10-15$ & Faton \\
\hline Histoires vraies & Historia & $8-12$ & Fleurus Presse \\
\hline Images DOC & Historia, ciencia, mundo, naturaleza & $8-12$ & Bayard \\
\hline Je Bouquine & Tout les goûts sont dans la lecture & $10-15$ & Bayard \\
\hline Je lis $D \dot{E} J \dot{A}$ & $\begin{array}{l}\text { Le premier livre á lire tout seul } \\
\text { Incentivar la lectura }\end{array}$ & $7-10$ & Fleurus Presse \\
\hline Le Belles Histoires & Lectura & $4-8$ & Bayard \\
\hline $\begin{array}{l}\text { JdE. Le journal des } \\
\text { enfants }\end{array}$ & Actualidad & $8-14$ & $\begin{array}{l}\text { Société Alsacienne } \\
\text { de Publications }\end{array}$ \\
\hline Le Monde des ados & Actualidad & $\begin{array}{l}\text { No } \\
\text { especifica }\end{array}$ & $\begin{array}{l}\text { Junior Hebdo Presse } \\
\text { Fleurus }\end{array}$ \\
\hline $\begin{array}{l}\text { Le P'tites filles à la } \\
\text { vanille }\end{array}$ & $\begin{array}{l}\text { Manualidades, recetas de cocina, } \\
\text { lectura }\end{array}$ & $3-5$ & Fleurus Presse \\
\hline Le petit LEONARD & Le magazine d'initiation à l'art & $6-13$ & Faton \\
\hline $\begin{array}{l}\text { Les P'tites } \\
\text { Princessess }\end{array}$ & Lectura, manualidades & $5-8$ & Fleurus Presse \\
\hline $\begin{array}{l}\text { Les p'tites } \\
\text { sorciéres }\end{array}$ & $\begin{array}{l}\text { Concursos, manualidades, recetas, } \\
\text { naturaleza }\end{array}$ & $8-12$ & Fleurus Presse \\
\hline $\begin{array}{l}\text { Mille et une } \\
\text { histoires }\end{array}$ & Lectura & $3-7$ & Fleurus Presse \\
\hline$O K A P I$ & $100 \%$ ADO. Le monde s'agrandit & $10-15$ & Bayard \\
\hline Papillote & $\begin{array}{l}\text { Le magazine pour les enfants. La } \\
\text { cuisine des petits chefs }\end{array}$ & $\begin{array}{l}\text { No } \\
\text { especifica }\end{array}$ & $\begin{array}{l}\text { Group Hommell } \\
\text { Societè Papillote }\end{array}$ \\
\hline Papoum & Inicio a la lectura, vocabulario, & $1-3$ & Fleurus Presse \\
\hline PHOSPHORE & Vos annés lycée & $14+$ & Bayard \\
\hline Picoti & $\begin{array}{l}\text { Dibujo, identificación de palabras y } \\
\text { recortables }\end{array}$ & $\begin{array}{l}9 \text { meses-3 } \\
\text { años }\end{array}$ & Milan \\
\hline Piroutte & Lectura, juegos, historia, & $5-8$ & Fleurus Presse \\
\hline Popi & $\begin{array}{l}\text { Inicio en la lectura, vocabulario, } \\
\text { recortables }\end{array}$ & $1-3$ & Bayard \\
\hline Pomme d'api & Lectura, juegos & $3-7$ & Bayard \\
\hline $\begin{array}{l}\text { Science et Vie } \\
\text { Découvertes }\end{array}$ & $\begin{array}{l}\text { Actualidad científica y tecnológica, } \\
\text { experiencias }\end{array}$ & $7-12$ & $\begin{array}{l}\text { Groupe Mondadori } \\
\text { France }\end{array}$ \\
\hline $\begin{array}{l}\text { Science et Vie } \\
\text { JUNIOR }\end{array}$ & $\begin{array}{l}\text { Actualidad científica y tecnológica, } \\
\text { experiencias }\end{array}$ & $13+$ & $\begin{array}{l}\text { Groupe Mondadori } \\
\text { France }\end{array}$ \\
\hline Toupi & Lectura y juegos & $3-6$ & Milan \\
\hline Tout comprendre & Ciencia, naturaleza, cuerpo humano & $8-12$ & Fleurus Presse \\
\hline Tout sur L'histoire & Historia & $14+$ & Fleurus Presse \\
\hline Tralalire & Inicio a la lectura & $2-5$ & Bayard \\
\hline Virgule & $\begin{array}{l}\text { Le magazine de français et de } \\
\text { littérature pour les } 10-15 \text { ans }\end{array}$ & $10-15$ & Faton \\
\hline
\end{tabular}




\begin{tabular}{|l|l|l|l|}
\hline Wapiti & Mission science passion nature & $7-13$ & Milan \\
\hline $\begin{array}{l}\text { Youpi. J'ai } \\
\text { compris! }\end{array}$ & Mundo, hombre, vida, naturaleza & $5-8$ & Bayard \\
\hline
\end{tabular}

En España, la población menor de 15 años asciende a casi siete millones y medio de habitantes, lo que constituye un $16,1 \%$ sobre el total. Este mismo porcentaje en Francia es notablemente superior ya que el segmento poblacional en esta franja de edad alcanza casi los doce millones, lo que conforma el $18.5 \%$ sobre la población total. (INE, 2014: www.ine.es). Notablemente, el público potencial francés inferior a 15 años supera aproximadamente en cuatro millones y medio al español. Estos números ayudaran a clarificar la gran diferencia en la producción periodística entre estos dos países vecinos, además, qué duda cabe, de los niveles de lectura que el país galo mantiene, son muy superiores a nuestro país.

\section{Naturaleza, contenidos y propósitos educativos}

Algunos autores adjudican a este tipo de prensa diversos factores positivos, entre los que destaca la afición lectora que puede provocar. También el que favorezca un aprendizaje evolutivo en el comportamiento social, el que potencie el vocabulario y aporte mayor conocimiento e información tanto personal como exterior. Se consigue así que el niño aprenda a razonar y a crear por sí mismo enlaces causales y psicológicos que le ayude a interpretar la realidad por sí mismo.

Lo característico de estas revistas es su firme propósito por estimular la imaginación, despertar la curiosidad y permitir desarrollar habilidades como la lectura. Con estos lemas, estos productos se afanan en crear objetivos específicos asociados a franjas de edad. Una de las mayores preocupaciones de la prensa infantil y juvenil es según Charon iniciar a futuros lectores y prepararlos como futuros consumidores de prensa (Charon, 2002: 177). De la misma opinión es el director de la revista Muy Interesante Junior, José Pardina: "De momento nos conformamos con despertar en los más pequeños el hábito de la lectura de prensa periódica y de alimentar su curiosidad de una manera honrada. No los tratamos como críos, sino como personas"s.

El objetivo de la prensa infantil y juvenil es desacralizar la lectura y no vincularla con una tarea asociada a la escuela, lo que pudiera entrañar obligación. Se trata por tanto de establecer una relación triangular entre el colegio, la familia y el niño lector. El objetivo que se persigue es iniciar en la lectura de una manera lúdica. En el nivel de primaria, estos productos son utilizados en Francia como complemento de clase (Consigny, 2009: 44).

La diversificación de contenidos en una misma revista invita a varios tipos de lectura. Por ejemplo, en la revista Leo Leo o Reportero Doc se ofrecen textos que requieren una concentración profunda y textos más trasversales y más ligeros de leer a través de diferentes formatos: historias, correo de lectores, reportajes, recetas de cocina, tru-

5 Entrevista a José Pardina, director de publicaciones de la revista Muy Interesante Junior. 10 de octubre de 2011. 
cos, etc. El objetivo que busca la revista es informar, documentar, distraer y producir una reflexión. Algunas cabeceras reciben el feedback de sus lectores a través de varios canales. Los lectores pueden enviar dibujos, fotos, cartas y participar en debates y concursos. Existe por tanto una voluntad de hacer partícipe al lector de la concepción del producto periodístico invitándolo a sugerir contenidos para futuros números.

Una clasificación por edades permite estructurar el conjunto de revistas disponibles en el mercado. En Francia, el sindicato de la prensa infantil y juvenil dictaminó una división por tramos de edad. El reparto queda de la siguiente manera: "despertar" para los más pequeños, "infancia" para las cabeceras dedicadas a la lectura y "junior" para los mayores de 8 años (Consigny, 2009:35).

En el caso francés, el target más joven de este tipo de productos son los niños de 0-3 años. Revistas como Tralalire, Toupi, Pomme D'api, Histoire pour le petits y Picoti constituyen textos para incentivar la lectura a través de cuentos cortos con ilustraciones vistosas y muy cuidadas o bien palabras sueltas escritas tanto en minúscula como en mayúscula para una mayor comprensión. Este tipo de publicaciones también incorpora juegos como recortables, dibujos para colorear, etc, haciendo de la revista un producto más completo. En el caso español, la revista equivalente es Popi.

Para el segmento a partir de 3-6, las revistas que se ofrecen en el mercado buscan atraer la atención de los jóvenes lectores a través de juegos, lectura, información de actualidad, humor, experimentos científicos, mundo animal, medio ambiente, historia y arte. Constituyen sin duda productos muy bien elaborados con gran aportación de fotografías, dibujos e ilustraciones y textos que igualmente estimulan la lectura. En el caso español destaca Leo Leo.

A partir de 6-7 años, la concepción del mundo en esta edad es la base para el diseño de estas revistas. El objetivo que persiguen sus editores, bajo el prisma de la lectura y la imagen, es aportar al lector una visión del mundo a través de temáticas que puedan atraer su interés. Se pretende buscar la espectacularidad de anécdotas en áreas como la ciencia, la astronomía, el medio ambiente, el mundo animal, el bricolaje, la moda, la cocina, etc.

La naturaleza, el medio ambiente y el mundo animal constituyen una baza muy reiterativa en este tipo de cabeceras. La preponderancia de la fotografía enluce a las revistas y las presenta como un producto final muy atractivo.

Existen pocas cabeceras que tengan por objetivo la actualidad informativa en términos generales. En el caso francés podemos destacar Le journal des enfants, editado desde la Societé Alsacienne de publication. Se trata de un rotativo que informa de la actualidad, a través de las secciones clásicas de un periódico para adultos, pero adaptado a adolescentes. En el caso español destaca la revista El Gancho, como publicación gratuita editada por la Junta de Andalucía, de distribución en colegios.

La mayoría de las revistan indican en portada la edad recomendada a la que van dirigidas. Según el criterio editorial de Bayard cada rango de edad contempla una meta educacional que alcanzar a través del producto. No obstante, algunas cabeceras omiten la edad a la que van dirigida (target), lo que puede deberse a dos aspectos: práctico (se justifica con las etapas del desarrollo evolutivo de Piaget, no corresponde siempre la edad con el desarrollo del niño), comercial (estrategia de ventas) (Decrozant, 2012). 
En relación a la periodicidad, estos productos suelen ser principalmente mensuales salvo algunas excepciones en las que la frecuencia llega a ser quincenal. Las revistas estudiadas no incluyen publicidad en su gran mayoría, siendo el precio por la suscripción anual la principal fuente de financiación. El precio de cada ejemplar está entre los 3.50 y los 5 euros.

\section{Fortalezas y debilidades del sector}

Las bazas con las que juega este sector de la prensa siguen siendo su fortaleza frente al panorama de la crisis económica que no ha afectado sobremanera a este tipo de cabeceras: su gran calidad de contenidos y la estrecha y privilegiada relación con su público lector. Así mismo, sus objetivos se mantienen intactos: promover la lectura y despertar la curiosidad entre sus lectores sobre el entorno que los rodea.

Lógicamente, el obstáculo al que se enfrenta este tipo de prensa está definido por el segmento de edad al que se orienta. En España, el público potencial de la prensa infantil y juvenil está representado por aproximadamente 7 millones de lectores entre 1 a 15 años, lo que constituye el 15\% del total de la población (INE, 2014: www.ine.es). La heterogeneidad de este amplio grupo de edad implica que un mismo periódico o revista no puede atender las necesidades de un lector de 5 años con otro de 13 años. En este sentido, cada título dispone aproximadamente de una audiencia aproximada de 2 millones de lectores, entendiendo que las cabeceras disponibles están orientadas a franjas de edad que van desde los 0 a 3,3 a 6,9 a 12 , etc.

Por último, hay que tener en cuenta que el público potencial en su crecimiento va ocupando franjas de edad diferentes, lo que implica que el editor debe hacer frente sistemáticamente a la captación de nuevos lectores. Se trata por tanto de un target que se renueva con rapidez. Ante este panorama, el objetivo de la empresa editora es fidelizar al lector con la marca para que renueve el consumo de prensa en otras edades pero sin variar la editorial.

La fotografía es un elemento escasamente utilizado en las revistas dedicadas a los más pequeños, principalmente entre 0 a 3 años. Su presencia suele ser mayor en prensa para lectores a partir de 3-5 años, etapa que corresponde con una mayor necesidad visual por parte del niño y se configura como un instrumento de comunicación y de aprendizaje. Para un público más avanzando en edad (de 8 a 12 años) la fotografía sí se establece como un componente de mayor importancia (Charon, 2002: 98).

El uso de fotografías en las revistas para lectores a partir de 8 años preferentemente viene precedido de un complemento didáctico que permite interpretar la imagen con mayor facilidad. Se trata de la inserción de personajes animados en la ilustración como agentes auxiliares que explican el significado a través de viñetas o 'bocadillos'. Una segunda técnica es la inserción de textos explicativos de corta extensión que aclaran algún detalle de difícil interpretación. Una última modalidad es dotar de palabras a una persona de la fotografía haciendo uso nuevamente de la técnica del cómic ofrecer información.

Las revistas difunden imágenes con niños de la misma edad a la que van dirigidas, siendo ésta una manera de integrar e identificar al conjunto de lectores con imágenes de su vida cotidiana y entornos más comunes como el colegio, el parque y la casa (Charon, 2002: 142). 
Otras fotografías muestran la vida en familia, en vacaciones o en escenas cotidianas, con animales, haciendo manualidades, cocinando en familia, etc. El grupo de amigos también representa un porcentaje importante a destacar. Detalles como la diversidad racional, el género y los distintos tipos de familias son detalles que se cuidan con esmero dentro de las redacciones. La presencia de los progenitores o tutores es escasa en revistas orientadas a un público juvenil. La existencia de alguna persona adulta está vinculada a su rama como profesional, mientras que en las publicaciones destinadas más a un público infantil sí pueden existir imágenes con padres compartiendo actividades con sus hijos. El esquema de familia tradicional rara vez evitando así marginar otras estructuras familiares.

La prensa infantil y juvenil constituye un producto muy elaborado para el que un equipo amplio de profesionales trabaja con objetivos muy específicos. El perfil del periodista que interviene en este tipo de prensa dista mucho de asemejarse con el prototipo de trabajador de publicaciones para un lector adulto.

La editorial Bayard acompaña a la promoción de sus revistas el siguiente mensaje: "publicación realizada por expertos en educación". Es interesante analizar esta finalidad, y para ello hay que detenerse en analizar el perfil del profesional que trabaja en este tipo de publicaciones periódicas.

En el caso de Bayard, las revistas que se venden en España son adaptaciones de los títulos franceses. Según Eva Frutos, "se traducen y adaptan y se crean algunos contenidos referidos a España. En Reportero Doc, un 5\%, y en Okapi, un 35\%.

La plantilla de trabajadores se complementa con comités especializados que asesoran desde el punto de vista lingüístico, estético, documental, fotográfico, etc, los contenidos. Así, los equipos están formados por profesionales de la educación, filología, pedagogía, psicología, ciencia así como expertos en la ilustración y la lingüística.

Al igual que en el sector de la prensa en general, las publicaciones periodísticas orientadas a un público infantil y juvenil deben hacer frente a nuevos retos en paralelo a la proliferación de medios multimedia. Las últimas novedades del mercado apuntan hacia un sistema de prensa digital para los más jóvenes. Así, la mejor revista para niños en el año 2013 según la Digital Magazine Award es Timbuktu Labs, Inc., revista digital (formato App para Ipad) que mereció el calificativo de "impresionante, con un diseño único". Asimismo ha merecido el premio al Mejor Diseño Award por Launch Edu\&Kid 2012. Los creadores de la revista son Elena Favilli, Francesca Cavallo y Trevor Lendeen y la ilustración corre a cargo de Philip Giordano, Marco Goran Romano, Daniel Kondo, entre otros. Ambos equipos trabajan en la intersección del diseño, la tecnología y lo educativo. La revista está dirigida a un público de 6 a 10 años, y sus actividades están basadas en la pedagogía de las escuelas de Regio Emilia, es decir, están diseñadas para cumplir estándares educativos basados en la imaginación, la comunicación, la belleza, la creatividad, la calidad, el respeto, la honestidad y el coraje. El enfoque es divertido, innovador, desafiante y sumamente creativo.

La App se presenta en inglés y en español y los diferentes números están dedicados a contenidos matemáticos, experimentales, históricos, literarios, utiliza estrategias interactivas y posibilita la comunicación con la propia editorial así como con 
otros lectores, o incluso amigos /as del lector. Incorpora sonidos y elementos visuales muy llamativos, junto a puzzles, ruleta de preguntas, creación de muñecos, recetas de cocina, vínculos a otras apps, cuentos medio-ambientales con historias de animales y posibilidades de escribir cuentos y mandárselo a la editorial de la revista.

\section{Conclusiones}

Podemos concluir tras nuestro estudio que la prensa infantil en España sigue ofreciéndose como lectura educativa a las jóvenes generaciones. El propósito de aficionar a la lectura, así como el de preparar a los lectores de prensa, que no ya solo de libros como en su día apuntara Chivelet (2008), es una de sus fortalezas más patente y ello desde una prensa infantil de calidad, motivadora, lúdica y con contenidos cercanos a los lectores. Además su especificidad viene determinada por la heterogeneidad de un público que accede a su lectura por impulso o por sugerencia de los iguales. Ello obliga al sector a la búsqueda continua de estrategias que logren fidelizar a este público, al menos con la marca editorial, dando así solución eficaz a la dinamidad que ha caracterizado a este sector desde sus orígenes. El interés de captar a los agentes socializadores como la escuela y la familia nos parece asimismo una constante digna de tener en cuenta. Aunque ahora prime el intento de participar y compartir en lo que constituye una apertura a nuevos intereses y nuevos aprendizajes sociales de las jóvenes generaciones. Lo que obviamente redunda en la calidad del producto. En palabras de Eva Frutos, el sector de la prensa infantil y juvenil con un aporte didáctico "tiene futuro porque la educación es esencial para la sociedad". Según Córdoba del Águila, "el sector goza de mejor salud que el resto de la prensa, porque hace diez años casi no existía y la editorial Panini ha conseguido que se abra un hueco en el quiosco para estas publicaciones" $"$.

A pesar de las buenas intenciones y del análisis prospectivo en positivo que ofrecen los profesionales, el sector de la prensa infantil y juvenil en España es aún muy desconocido y queda solapado por la ingente demanda de prensa y revistas de carácter comercial, cuyo contenido ideológico es bastante cuestionable. La suscripción sólo es de utilidad para revistas con pocas ventas y no vinculadas a fenómenos mediáticos. Sin embargo, queda latente entre el público lector una necesidad de conocer mejor estos productos, siendo el boca a boca una herramienta de propagación lenta.

Por otro lado, siendo baja la oferta disponible en el mercado, este sector se ofrece como un posible nicho de mercado para futuros profesionales.

\section{Referencias bibliográficas}

AA.VV. (1981): Prensa infantil y Educación, Edicions de la Universitat de Barcelona. AIMC (2008): Audiencia Infantil/Juvenil de medios en España.

ABRIL, Paco y LÓPEZ, Ana (2000): "La oreja verde”, INFANCIA, 60, pp. 25-31.

${ }^{6}$ Entrevista a José Luis Córdoba del Águila, director de publicaciones de la revista National Geographic Kids. 10 de octubre de 2011. 
AGNÉS, Jean; LANDA, Fernande; y SERRYN, Dominiquine (1988): La presse des jeunes. Colection L'ecole des Parent, Ed. Sytos, París.

AVACU y Dirección General de Evaluación, Innovación y Calidad Educativa y de Formación Profesional (2010): Influencia de las revistas en niños y jóvenes. Valencia.

BARRERO, Manuel (2011): “Orígenes de la historieta Española 1857-1906”. Arbor, CLXXXVII, pp. 15-42.

BORDA CRESPO, $\mathrm{M}^{\mathrm{a}}$ Isabel (2002): Literatura infantil y juvenil. Teoría y didáctica. Granada, Grupo Editorial Universitario.

BORDA CRESPO, Ma Isabel (2006): Cómo iniciar a la lectura. Málaga, Arguval.

BRAVO VILLASANTE, Carmen (1979): Historia de la literatura infantil Española. Madrid, Escuela Española.

CHARON, Jean-Marie (2002): La presse des jeunes. Éditions La Découverte.

CHIVELET, Mercedes (2008): "La prensa infantil y juvenil como inductora del libro", Lazarillo, 20, pp. 25-34.

CONSIGNY, Camille (2009): La presse jeunesse en Frances: enjeux passés et défis actuels. Bordeaux, Université de Bordeaux.

COSÍN PUJOL, Belén (2003): "La prensa infantil y juvenil actual”. CLIJ, 16, 160, pp. 29-36.

DECROZANT, Camille (2012): La photographie dans la presse jeunesse: une fenetre qui s'ouvre sur le monde: analyse d'une éducation à l'image et par l'image. [Memoria académica, inédita]. Bordeaux, Université de Bordeaux.

ESPIÑO ROSENDE, María Jesús (2014): "Las revistas infantiles como producto de consumo y medio publicitario" en ACTAS ICONO 14- $\mathrm{N}^{\circ} 15$, I Congreso Internacional de Comunicación Infantil, pp. 69-83.

FUENTES, Juan Francisco (2003): "El público del libro y la prensa (1808-1868)”, en INFANTES, Victor et al. (Dir.): Historia de la edición y de la lectura en España (1472-1914). Madrid, Fundación Germán Sánchez Ruipérez, pp. 724-734.

INE. Instituto Nacional de Estadística (2014): Revisión del Padrón a 1 de enero de 2014.

MARTÍN, Antonio (2004): "100 años de prensa infantil catalana", CLIJ, 17, 173, pp. 44-56.

MARTÍN, Antonio (2011): "Las aleluyas, primera lectura y primeras imágenes para niños en los siglos XVIII-XIX. Un antecedente de la literatura y la prensa infantil en España”, Espéculo, Revista de estudios literarios, 47.

MILLOT, Sara (2011): Nos enfants et leur presse. Cap Canal [éd., distrib.] Allée de l'enfance.

QUINTANA CABANAS, Josep María (1981): "Prensa infantil y educación informal”, en AA.VV. Prensa infantil y educación, pp. 59-72. 
REVILLA, Federico (1981): "Un estudio psico-sociológico sobre TBO (1947-1979)", en AA.VV. Prensa Infantil y educación, pp. 35-58.

RUBIO GIL, Ángeles et al. (2008): Influencias de las revistas juveniles en la sexualidad de las y los adolescentes, CIDE/ Instituto de la Mujer. 